\title{
SCRATCH THAT! - Two case reports of scratch-card gambling disorder
}

\author{
Catarina Raposo-Lima ${ }^{\text {a,b,c }}$, Liliana Castro a , Nuno Sousa ${ }^{\text {b,c }}$, Pedro Morgado ${ }^{\text {b,c,d, } *}$ \\ a Hospital de Magalhães Lemos E.P.E., Rua Professor Álvaro Rodrigues, 4149-003 Porto, Portugal \\ ${ }^{\mathrm{b}}$ Life and Health Sciences Research Institute (ICVS), School of Health Sciences, University of Minho, 4710-057 Braga, Portugal. \\ c ICVS-3Bs PT Government Associate Laboratory, School of Health Sciences, University of Minho, Braga, 4710-057 Guimarães, Portugal \\ ${ }^{\mathrm{d}}$ Hospital de Braga, Sete Fontes - São Victor, 4710-243 Braga, Portugal
}

\section{H I G H L I G H T S}

- Scratch-card lottery is a very popular form of gambling and has addictive potential.

- Disordered gambling is often under-recognized although it has serious consequences.

- Scratch-card gambling disorder is extremely uncommon.

- Psychiatric comorbity is frequent among gamblers.

- Approved treatment strategies are lacking, so early recognition of cases is key.

\section{A R T I C L E I N F O}

Available online 19 January 2015

Keywords:

Gambling disorder

Behavioral addictions

Scratch-cards

Lottery

Case report

\begin{abstract}
A B S T R A C T
Gambling disorder is a common, clinically relevant condition that impacts significantly one's life. Given that approved pharmacological interventions are lacking, it is crucial to readily identify these cases to provide available interventions in psychiatric care services. Here, we present two uncommon cases of unique scratchcard gambling disorder, a specific type of pathological gambling that could be increasing as availability of these games are growing.
\end{abstract}

(c) 2015 Elsevier Ltd. All rights reserved.

\section{Introduction}

Over the last several years, there has been a rapid increase in the accessibility to legalized forms of gambling in many countries around the world. Despite being a widespread activity, only a minority of people (ranging from 0.02 to $2 \%$ ) develop gambling disorder (GD) in the general adult population; additionally $0.1-4.5 \%$ of subjects develop problematic gambling behavior, that yet do not meet the DSM-5 criteria for the disorder (Sassen, Kraus, \& Bühringer, 2011).

Pathological gambling, an entity first introduced in the Diagnostic and Statistical Manual of Mental Disorders of the American Psychiatric Association in 1980 (APA, 1980) and originally classified as an "impulsecontrol disorder not elsewhere categorized", has been recently renamed to "gambling disorder" and moved to the "Addiction and Related Disorders" category in the DSM-5 (APA, 2013). This reclassification

\footnotetext{
* Corresponding author at: Life and Health Sciences Research Institute, University of Minho, Campus de Gualtar, 4710-057 Braga, Portugal. Tel.: + 351253604931.

E-mail addresses: catarinalima@ecsude.uminho.pt (C. Raposo-Lima), LilianaCastro@hmlemos.min-saude.pt (L. Castro),njcsousa@ecsaude.uminho.pt (N. Sousa), pedromorgado@ecsaude.uminho.pt (P. Morgado).
}

reflects the conceptualization of GD as a non-substance or "behavioral" addiction (Blanco, Moreyra, Nunes, et al., 2001; el-Guebaly, Mudry, Zohar, et al., 2012; Holden, 2001; Potenza, 2006), and support for this notion has come not only from a number of shared clinical, phenomenological and epidemiological features, but also from biochemical, neuroimaging, genetic and treatment studies (for reviews see Ibáñez, Blanco, Castro, et al., 2003; Goudriaan, Oosterlaan, de Beurs, et al., 2004; Grant, Brewer, \& Potenza, 2006; Potenza, 2008; van Holst, van den Brink, Veltman, et al., 2010; Probst \& van Eimeren, 2013; Zakeri \& Potenza, 2012; Goudriaan, Yücel, \& van Holst, 2014).

Core clinical features of GD include repetitive or compulsive engagement in a behavior despite its adverse consequences, diminished control over the problematic behavior, an appetitive urge or craving state prior to the engagement in the behavior, and a hedonic quality during the performance of the behavior. Aspects like tolerance, withdrawal, unsuccessful attempts to cut back or stop the behavior and interference in major areas of functioning are also described (Castellani \& Rugle, 1995; Grant et al., 2006; Griffiths, 1993; Potenza, 2006; Zakeri \& Potenza, 2012). According to the DSM-5, to receive the diagnosis of GD an individual must meet at least four of nine diagnostic criteria, which must occur within a 12-month period; both the 
threshold for diagnosis and the time frame for symptoms are new to this DSM version.

Interestingly, this maladaptive pattern of gambling behavior is more common in males and usually initiates during adolescence or young adulthood. Women show a tendency to begin later in life, but seem to demonstrate a more rapid progression from initial engagement to addiction (the so-called telescoping process) (George \& Murali, 2005; Potenza, Fiellin, Heninger, et al., 2002).

High rates of psychiatric comorbidity in people with GD have been reported. Most studies revealed an increased prevalence of substanceuse disorders, anti-social personality disorder, mood disorders, and impulse-control disorders (Chou \& Afifi, 2011; Cunningham-Williams, Cottler, Compton, et al., 1998; Lynch, Maciejewski, \& Potenza, 2004; Potenza et al., 2002). GD is a debilitating disorder, which impacts significantly on different aspects of life and carries an additional mortality risk among sufferers, mainly related to suicide (George \& Murali, 2005; Sood, Pallanti, \& Hollander, 2003). Poor performance at work, absenteeism, job loss and family problems have all been related to this disorder (Grant, Odlaug, \& Schreiber, 2012).

Given its prominence, the management of GD has been the focus of many researchers. A variety of drugs have been studied so far, including anti-depressants (paroxetine, fluvoxamine, sertraline, and bupropion), opioid antagonists (naltrexone, nalmefene), mood stabilizers (lithium, topiramate), atypical anti-psychotics (olanzapine) and other agents, such as N-acetyl cysteine and modafinil (for reviews see Sood et al., 2003; Grant et al., 2012). The most consistent data come from four randomized, double-blind, placebo-controlled trials in which opioid antagonists revealed to be superior to placebo (Grant, Kim, Hollander, et al., 2008; Grant et al., 2006; Kim, Grant, Adson, et al., 2001). However, despite the growing number of studies on the pharmacological management of GD, no medication has yet been approved as a treatment (Grant et al., 2012; Sood et al., 2003; Zakeri \& Potenza, 2012). Further research in this field is warranted in order to reduce gambling-related problems and improve quality of life.

Although a wide variety of games of chance are available, not all have the same addictive potential, which is related to the structural characteristics of the game. Like traditional lotteries (less addictive), scratch-card (or instant) lottery requires no skill, has a low probability of winning and a low payout ratio. However, it may be viewed as moderately addictive since it shares some of the features of more addictive forms of gambling (slot machines). Similar to slot machines, scratch-cards have short payout schedules coupled with a rapid event frequency (i.e., not only is the interval between the initial gamble and winning payment short, the loss period is also brief). Other similarities include the possibility to rapidly regamble the winnings and the high frequency of near misses (i.e., failures that are close to being successful). All these features act as extrinsic reinforcers, inducing winners to continue gambling. Furthermore, scratch-cards are somewhat inexpensive, widely available and advertised, which contributes to increase its addictive potential (Ariyabuddhiphongs, 2011; DeFuentes-Merillas, Koeter, Bethlehem, et al., 2003; DeFuentes-Merillas, Koeter, Schippers, et al., 2004; Griffiths, 2000; Hendriks, Meerkerk, van Oer, et al., 1997).

In contrast with other forms of gambling, governments use lottery and scratch-card gambling as a way to increase income and spend large sums of money in advertising so as to encourage people to engage in these types of gambling.

Since its introduction, lotteries have become the most common form of gambling in many countries. Scratch-card lottery sales have been escalating and represent the most popular type of lottery among youth (SCML, 2013; Griffiths, 2000; Wood \& Griffiths, 2004; Rahman, Pilver, Desai, et al., 2012). Recent reports from Portugal indicate 50\% of individuals with ages comprising from 15 to 24 years old have gambled for money, with $18.3 \%$ of those reporting scratch-card lottery gambling (Balsa, Vital, \& Urbano, 2013). This is a matter of concern, given problematic gambling during adolescence may be linked to poorer functioning later in life (Lynch et al., 2004). However, the prevalence of scratch-card related problems is rather low, and only few studies exist that have explored this issue (Hendriks et al., 1997; Griffiths, 2000; Frost, Meagher, College, et al., 2001; DeFuentes-Merillas et al., 2003, 2004; Ariyabuddhiphongs, 2011). One such study points to a $0.24 \%$ prevalence of scratch-card GD; of those, only $0.09 \%$ was addicted uniquely to scratch-cards (DeFuentes-Merillas et al., 2003).

Because unique scratch card gambling issues are so uncommon and often under recognized, and the impact of GD is so important, we herein report two such cases of GD in adult individuals, who presented themselves to medical assistance due to the negative consequences of their maladaptive behavior. Both patients were assessed, diagnosed and treated by senior psychiatrists. Both cases were recruited at the psychiatric emergency department and referred to the outpatient clinic. GD was diagnosed using DSM-5 criteria. Both patients agreed on the publication of their anonymized cases.

\section{Case study 1}

A 38 year-old woman, married, with two children, with no previous relevant medical history, referred herself to the psychiatric emergency room with a 2-year history of compulsive gambling behavior. She started by gambling daily, spending small amounts of money on scratch-cards. Her bets increased progressively so as to keep a certain level of excitement and, at the time of referral, she reported average losses of 2000 to $3000 €$ a month. She did not report any other kind of gambling or addictive behavior. Given the $485 €$ monthly salary, this patient rapidly developed financial issues and not only relied on others to solve these problems and keep her gambling habits, she also used her company's funds. Eventually, she lost her job and marital problems arose, which contributed to increase gambling episodes. Apart from the gambling disorder, this patient had no past history of other psychiatric disorder and was not under any medication at the time of assessment. Although she had full insight of her condition, she demonstrated a clear misperception of the probabilities of winnings, believing she could solve her problems if she'd won a prize. The patient did not present any psychotic symptoms; organic disease was also excluded. Because she described an intense feeling of anxiety that alleviated with gambling and strong impulses to gamble, she was then medicated with increasing doses of fluoxetine until $60 \mathrm{mg}$ /day and topiramate 50 $\mathrm{mg} /$ day and managed to stay abstinent for 20 months. Ultimately, she stopped taking her medication, leading to a relapse, with bets around $100-150 € /$ day on instant lottery tickets. She resumed consultation and the same treatment and hasn't gambled since.

\section{Case Study 2}

A 51 year-old man, living with his wife and son, referred himself to the psychiatric emergency room after familial conflicts due to excessive losses on scratch lottery tickets. The patient reported a history of regular compulsive gambling that had started two years prior. Scratch-card gambling had begun in his late twenties, but the occasional small spendings evolved to a more regular pattern of gambling over several years. However, only recently (last two years) did this behavior become maladaptive: preoccupation with gambling increased, episodes became more frequent and bets were larger. Gambling episodes eventually increased in response to specific stressful events, mainly family problems. There was no engagement in other forms of gambling. At the time this patient came to our attention, he reported to buy scratch-cards almost every day, driven by an irresistible urge to gamble, with average losses of 200-300€ a month on scratch lottery tickets only. Given his $485 €$ monthly salary, he admitted to have recently asked for a loan in order to keep gambling, and financial and marital issues were now arising. He claimed never to have asked for specialized help to stop gambling, although he had tried on his own, unsuccessfully. This patient had a past history of alcohol dependence, currently being abstinent for almost 20 years, and reported a family history of alcohol 
dependence (both parents and a sister). He kept a daily consumption of 6-8 coffees and 2-3 packs of cigarettes; there was no consumption of other substances. The patient also had a prior history of recurrent depression, being already followed as an outpatient and medicated with citalopram $40 \mathrm{mg} /$ day, mirtazapine $30 \mathrm{mg} /$ day, diazepam $10 \mathrm{mg} /$ day and olanzapine $10 \mathrm{mg} /$ day. He described himself as an impulsive person, and although he claimed to understand the negative consequences of his addictive behaviors, he said he simply could not resist the urge to gamble, have coffee or smoke. Organic disease was discarded. The patient was referred back to the outpatient clinic. Since he already was medicated for depressive, anxious and impulsive symptoms, therapeutical optimization by more specifically targeting GD (i.e. by using an opioid antagonist) was suggested.

\section{Discussion}

This paper presents two cases of GD in which patients came to medical attention after years of excessive and disruptive gambling behavior, namely unique scratch card gambling. Both individuals can be diagnosed as disordered gamblers according to DSM-5, since they fulfill the diagnostic requirements stated earlier. They describe an irresistible urge to gamble that has progressively worsened throughout the years, with increasing preoccupation with gambling and a need to raise their bets as a way to attain a certain level of excitement. Following their problematic behavior, familial, financial and occupational problems ensued.

Other typical aspects of GD can be found in both cases: one describes a young female adult who started gambling late in her life, and yet rapidly progressed to a gambling dependence; the other reflects a man with comorbid depressive disorder and previous alcohol dependence, with a history of occasional gambling in young adulthood that eventually evolved to a pattern of excessive and maladaptive behavior later in life. Both patients were aware of the adverse consequences of their actions, and recognized to gamble more frequently in response to stressful events, but despite their efforts they were not able to stop gambling. Marked impulsivity was also a prominent feature in both cases.

Concerning pharmacological management, both patients were prescribed with a selective serotonin reuptake inhibitor (SSRI). Although studies using these agents have yielded mixed results, some have demonstrated its efficacy in the treatment of GD. Specifically, citalopram treated patients showed significant improvement in gambling measures and quality of life (Zimmerman, Breen, \& Posternak, 2002). However, other factors justify the use of these agents in these cases. Patient 1 exhibited high levels of anxiety, which would benefit with this therapeutic strategy. Patient 2 was under maintenance therapy for a depressive episode; as such, it was considered reasonable to keep the ongoing treatment unchanged. Of note, this last patient reported a history substance use, which is commonly found alongside GD. Additionally, family history of alcohol dependence was present. A $\mu$-opioid antagonist could have been considered as potentially useful in the management of this patient, since evidence suggests a preferential response to these drugs by patients with history of substance use disorder or strong urges to gamble and a positive family history of alcohol dependence (Grant et al., 2008).

Although topiramate has been shown not to be effective in the treatment of GD, evidence suggests it may be useful in reducing impulsivity (Berlin, Braun, Simeon, et al., 2013), an aspect that led to its use in the management of patient 1.

Treatment selection for GD is not straightforward and current evidence does not point in any particular direction. Studies so far have shown some drugs (including antidepressants, mood stabilizers, antipsychotics and opioid antagonists) may be effective on the shortterm, but none has yet evaluated its long-lasting effects, which points to the need for longer duration, longitudinal studies. Moreover, the existing trials have been performed on small subsets of adult patients with GD, which may not be representative of the entire population of patients. Thus, it is important to carefully select a representative sample in future studies. Patient selection regarding comorbid conditions must also be taken into account; not only psychiatric comorbidity is especially common among these patients, it may determine the effectiveness of a particular drug and thus help in guiding the selection of treatment (for reviews see Sood et al., 2003; Grant et al., 2012; Zakeri \& Potenza, 2012).

\section{Conclusion}

Instant lottery gambling, although not as common as other forms of gambling, has been increasing, and since it is widely available and easily accessible, public health concerns arise. This form of gamble is under governmental regulation, but is also a source of revenue to the State, which brings about important issues regarding the prevention of gambling issues. Moreover, scratch-tickets are inexpensive, widely accepted by society and, consequently, represent an increasingly common form of gambling among adolescents. Data concerning prevalence rates of scratch-card GD are scarce, but nonetheless these cases are infrequent and often go under-recognized. We try to raise awareness for this issue by presenting two such cases. Additionally, the current strategies to manage these cases are quite ineffective and treatment options remain to be defined. As such, an earlier identification and characterization of gambling problems can contribute to a better understanding of GD, and to the optimization of therapeutical interventions. Further research is needed to unravel the mechanisms underlying GD and to improve the medical assistance of these patients.

\section{Role of funding sources}

There was no role for financial support at any stage of the study, elaboration of the manuscript or decision to submit the article for publication.

\section{Contributors}

Catarina Raposo-Lima and Pedro Morgado were responsible for examining and recovering patient's data. All authors conducted literature searches and provided information regarding previous research studies. Catarina Raposo-Lima wrote the first draft of the manuscript and Liliana Castro, Pedro Morgado and Nuno Sousa revised the manuscript. All authors contributed to and have approved the final manuscript.

\section{Conflict of interest}

None of the authors has conflicts of interest to declare.

\section{References}

American Psychiatric Association (APA) (1980). Diagnostic and Statistical Manual of Mental Disorders (3rd ed.). Washington, DC: APA.

American Psychiatric Association (APA) (2013). Diagnostic and Statistical Manual of Mental Disorders (5th ed.). Washington, DC: APA.

Ariyabuddhiphongs, V. (2011). Lottery gambling: A review. Journal of Gambling Studies, 27(1), 15-33.

Balsa, Vital, \& Urbano (2013). III Inquérito Nacional ao Consumo de Substâncias Psicoativas na População Geral - Portugal 2012. Lisboa: Serviço de Intervenção nos Comportamentos Aditivos e nas Dependências (SICAD): Divisão de Estatística e Investigação.

Berlin, H. A., Braun, A., Simeon, D., et al. (2013). A double-blind, placebo-controlled trial of topiramate for pathological gambling. The World Journal of Biological Psychiatry, 14, 121-128.

Blanco, C., Moreyra, P., Nunes, E. V., et al. (2001). Pathological gambling: Addiction or compulsion? Seminars in Clinical Neuropsychiatry, 6, 167-176.

Castellani, B., \& Rugle, L. (1995). A comparison of pathological gamblers to alcoholics and cocaine misusers on impulsivity, sensation seeking, and craving. The International Journal of the Addictions, 30, 275-289.

Chou, K. L., \& Afifi, T. O. (2011). Disordered (pathological or problem) gambling and axis I psychiatric disorders: Results from the National Epidemiologic Survey on Alcohol and Related Conditions. American Journal of Epidemiology, 173, 1289-1297.

Cunningham-Williams, R. M., Cottler, L. B., Compton, W. M., III, et al. (1998). Taking chances: Problem gamblers and mental health disorders results from the St. Louis Epidemiologic Catchment Area Study. American Journal of Public Health, 88, 1093-1096.

DeFuentes-Merillas, L., Koeter, M. W. J., Bethlehem, J., et al. (2003). Are scratchcards addictive? The prevalence of pathological scratchcard gambling among adult scratchcard buyers in the Netherlands. Addiction, 98, 725-731.

DeFuentes-Merillas, L., Koeter, M. W. J., Schippers, G. M., et al. (2004). Temporal stability of pathological scratchcard gambling among adult scratchcard buyers two years later. Addiction, 99, 117-127. 
el-Guebaly, N., Mudry, T., Zohar, J., et al. (2012). Compulsive features in behavioral addictions: The case of pathological gambling. Addiction, 107(10), 1726-1734.

Frost, R. O., Meagher, B. M., College, S., et al. (2001). Obsessive-compulsive features in pathological lottery and scratch-ticket gamblers. Journal of Gambling Studies, 17(1), 4-19.

George, S., \& Murali, V. (2005). Pathological gambling: an overview of assessment and treatment. Advances in Psychiatric Treatment, 11, 450-456.

Goudriaan, A. E., Oosterlaan, J., de Beurs, E., et al. (2004). Pathological gambling: A comprehensive review of biobehavioral findings. Neuroscience Biobehavioral Reviews, 28, 123-141.

Goudriaan, A. E., Yücel, M., \& van Holst, R. J. (2014). Getting a grip on problem gambling: what can neuroscience tell us? Frontiers in Behavioral Neuroscience, 8, 1-12.

Grant, J. E., Brewer, J. A., \& Potenza, M. N. (2006). The neurobiology of substance and behavioral addiction. CNS Spectrums, 11(12), 924-930.

Grant, J. E., Kim, S. W., Hollander, E., et al. (2008). Predicting response to opiate antagonists and placebo in the treatment of pathological gambling. Psychopharmacology, 200(4), 521-527.

Grant, J. E., Odlaug, B. L., \& Schreiber, L. R. N. (2012). Pharmacological treatments in pathological gambling. British Journal of Clinical Pharmacology, 77(2), 375-381.

Griffiths, M. (1993). Tolerance in gambling: An objective measure using the psychophysiological analysis of male fruit machine gamblers. Addictive Behaviors, $18,365-372$.

Griffiths, M. (2000). Scratchcard gambling among adolescent males. Journal of Gambling Studies, 16(1), 79-91.

Hendriks, V. M., Meerkerk, G. J., van Oer, H. A. M., et al. (1997). The Dutch instant lottery. Prevalence and correlates of at-risk playing. Addiction, 92, 335-346.

Holden, C. (2001). 'Behavioral addictions': Do they exist? Science, 294, 280-282.

Ibáñez, A., Blanco, C., Castro, I. P., et al. (2003). Genetics of pathological gambling. Journal of Gambling Studies, 19(1), 11-22.

Kim, S. W., Grant, J. E., Adson, D. E., et al. (2001). Double-blind naltrexone and placebo comparison study in the treatment of pathological gambling. Biological Psychiatry, 49, 914-921.
Lynch, W. J., Maciejewski, P. K., \& Potenza, M. N. (2004). Psychiatric correlates of gambling in adolescents and young adults grouped by age at gambling onset. Archives of General Psychiatry, 61, 1116-1122.

Potenza, M. N. (2006). Should addictive disorders include non-substance related conditions? Addiction, 101, 142-151.

Potenza, M. N. (2008). The neurobiology of pathological gambling and drug addiction: An overview and new findings. Philosophical Transactions of the Royal Society B, 363, 3181-3189.

Potenza, M. N., Fiellin, D. A., Heninger, G. R., et al. (2002). Gambling. An addictive behavior with health and primary care implications. Journal of General Internal Medicine, 17, 721-723.

Probst, C. C., \& van Eimeren, T. (2013). The functional anatomy of impulse control disorders. Current Neurology and Neuroscience Reports, 13, 386.

Rahman, A. S., Pilver, C. E., Desai, R. A., et al. (2012). The relationship between age of gambling onset and adolescent problematic gambling severity. Journal of Psychiatric Research, 46(5), 675-683.

Santa Casa da Misericórdia de Lisboa (SCML) (2013). Relatório e Contas do Departamento de Jogos da Santa Casa da Misericórdia de Lisboa. (Lisboa).

Sassen, M., Kraus, L., \& Bühringer, G. (2011). Differences in pathological gambling prevalence estimates: Facts or artefacts? International Journal of Methods in Psychiatric Research, 20(4), e83-e99.

Sood, E. D., Pallanti, S., \& Hollander, E. (2003). Diagnosis and treatment of pathological gambling. Current Psychiatry Reports, 5, 9-15.

van Holst, R. J., van den Brink, W., Veltman, D. J., et al. (2010). Brain imaging studies in pathological gambling. Current Psychiatry Reports, 12, 418-425.

Wood, R. T. A., \& Griffiths, M. D. (2004). Adolescent lottery and scratchcard players: Do their attitudes influence their gambling behaviour? Journal of Adolescence, 27, 467-475.

Zakeri, K., \& Potenza, M. N. (2012). The neuropsychopharmacology of pathological gambling. Current Psychiatry Reviews, 8(1), 20-24.

Zimmerman, M., Breen, R. B., \& Posternak, M. A. (2002). An open-label study of citalopram in the treatment of pathological gambling. Journal of Clinical Psychiatry, 63(1), 44-48. 